\title{
Nitric Dioxide and Acetone Sensors Based on Iron Oxide Nanoparticles
}

\author{
J. Ivančo ${ }^{1, *}$, Š. Luby ${ }^{1}$, M. Jergel ${ }^{1}$, P. Šiffalovič ${ }^{1}$, M. Benkovičová1, \\ Y. Halahovets ${ }^{1}$, E. Majková ${ }^{1}$, R. Rella ${ }^{2}$, and M. G. Manera ${ }^{2}$ \\ ${ }^{1}$ Institute of Physics, Slovak Academy of Sciences, Dúbravská. Cesta 9, 84511 Bratislava, Slovakia \\ ${ }^{2}$ Institute of Microelectronics and Microsystems, IMM-CNR, Unit of Lecce, 73100 Lecce, Italy
}

(Received: 31 August 2013. Accepted: 19 February 2014)

\begin{abstract}
The $\mathrm{Fe}_{2} \mathrm{O}_{3}$ and $\mathrm{CoFe}_{2} \mathrm{O}_{4}$ nanoparticle-based Langmuir-Blodgett films for sensing of nitric dioxide $\left(\mathrm{NO}_{2}\right)$ and acetone vapours have been explored. Both the sensitivity of the chemiresistors and dynamic properties, such as the response/recovery time, have been probed in dependence of the number of nanoparticle monolayers and working temperatures. The response of 23 at the $\mathrm{NO}_{2}$ concentration of $1 \mathrm{ppm}$, i.e., approaching the canine detection limit, has been monitored implying the appropriateness for the detection of nitrate-based explosives.
\end{abstract}

Keywords: Gas Sensor, Chemiresistors, $\mathrm{NO}_{2}$, Acetone Vapours, Nanoparticle Arrays, Langmuir-Blodgett Films.

\section{INTRODUCTION}

The real-time and areal monitoring of environmentally hazardous gases (e.g., $\mathrm{CO}, \mathrm{CO}_{2}, \mathrm{NO}, \mathrm{NO}_{2}, \mathrm{O}_{3}, \mathrm{SO}_{2}, \mathrm{Cl}_{2}$ ) and detection of various gaseous markers (e.g., $\mathrm{NO}_{x}$ of explosives) demand the development of affordable highlysensitive sensors capable of detection of certain gases in the ppm- and sub-ppm range. Particularly the chemiresistors, i.e., the solid-state gas-sensing devices changing their resistance upon the exposure to traces of a particular gas have received considerable attention. ${ }^{1}$ Sensing properties of the solid-state sensors prevailingly based on resistive metal oxides, such as $\mathrm{Ag}_{2} \mathrm{O},{ }^{2} \mathrm{Fe}_{2} \mathrm{O}_{3},{ }^{3} \mathrm{In}_{2} \mathrm{O}_{3},{ }^{4,5} \mathrm{SnO}_{2}$, , 7 $\mathrm{TiO}_{2},{ }^{8} \mathrm{WO}_{3},{ }^{9-12}$ and $\mathrm{ZnO},{ }^{13}$ are advanced by the nanostructuring of the sensing material (nanotubes, nanoparticles). On one hand, the nanostructuring increases the aspect ratio, i.e., the surface-to-volume ratio, besides it can lead to size-controlled specific effects. ${ }^{14}$

In this work, we will demonstrate the sensing properties of chemiresistors based on particular number of $\mathrm{Fe}_{2} \mathrm{O}_{3}$-and $\mathrm{CoFe}_{2} \mathrm{O}_{4}$-nanoparticle (NP) self-assembled monolayers toward $\mathrm{NO}_{2}$ and acetone vapours, the latter being applicable for the breath analysis of glycaemia patients. The sensing films have been prepared by means of the Langmuir-Blodgett (L-B) method, which allows the sequential preparation of particular nanoparticle

${ }^{*}$ Corresponding author; E-mail: jan.ivanco@savba.sk monolayers and thereby the controlled formation of the sensing film with targeted number of monolayers enabling to explore the effect of the film thickness on sensing properties.

\section{EXPERIMENTAL DETAILS}

The $\mathrm{Fe}_{2} \mathrm{O}_{3}$ and $\mathrm{CoFe}_{2} \mathrm{O}_{4}$ NPs have been synthesized via reaction between $\mathrm{Fe}$ and $\mathrm{Co}$ acetylacetone with oleic acid and oleylamine being the surfactant precursor in phenyl ether.

The average NP diameters have been of $6.4 \pm 0.6 \mathrm{~nm}$ and $7.6 \pm 0.6 \mathrm{~nm}$ for $\mathrm{Fe}_{2} \mathrm{O}_{3}$ and $\mathrm{CoFe}_{2} \mathrm{O}_{4}$, respectively, including the surfactant thickness of about $1 \mathrm{~nm}$. The sensing NP films have been prepared by the L-B deposition of colloid NPs onto alumina substrates equipped with interdigitated electrodes intended for the film resistivity determination. The investigated films consisted of arrays of 1 , 2, 4, 7, and 10 sequentially deposited NP monolayers. Particular monolayers were prepared from the water subphase at the surface pressure of $20 \mathrm{mN} / \mathrm{m}$.

The X-ray diffraction characterization was performed at grazing incidence (the incidence angle of 1 degree) using D8 Discover SSS (Bruker AXS) with rotating $\mathrm{Cu}$ anode.

The X-ray absorption near-edge structure (XANES) characterization was carried out in fluorescence mode at station $\mathrm{C}$ (CEMO) at the beamline DORIS III at 
HASYLAB of Deutsches Elektronen-Synchrotron (DESY) in Hamburg, Germany. ${ }^{15}$

The samples intended for the characterization of the sensing properties have been either annealed at $400{ }^{\circ} \mathrm{C}$ or UV-irradiated for $20 \mathrm{~min}$ in a reactor equipped with ozone generating mercury lamp $(h \nu=4.9 \mathrm{eV}$, irradiation power of $2 \mathrm{~mW} / \mathrm{cm}^{2}$ ) to stripe the organic surfactant.

The current response of NP layers was characterized upon the 100-sccm flow of dry air mixed with the required amount of $\mathrm{NO}_{2}$ or acetone vapours. The elevated working temperature has been attained by means of planar heaters fabricated on the back side of the alumina substrates.

\section{RESULTS AND DISCUSSION}

\subsection{Structural Properties of Films}

Figure 1(a) presents the scanning electron microscopy (SEM) mapping of one self-assembled nanoparticle monolayer. The stripping of the insulating surfactant (either by the UV irradiation exposure or by annealing) eventuates in discontinuities in 1 ML-thick films (Fig. 1(b)) and accordingly in the current response in the sub-nA range at the supply voltage of $5 \mathrm{~V}$. Employment of 2 and more ML of NPs preserves the continuous films even after the surfactant stripping and the current response increases to the $1 \mu \mathrm{A}$ range.

The thermal stability of NP layers has been investigated through the structure characterization by X-ray diffraction (XRD) upon the vacuum anneal up to $700{ }^{\circ} \mathrm{C}$. Figures 2(a) and (b) plot structure evolutions of the $\mathrm{CoFe}_{2} \mathrm{O}_{4}$ - and $\mathrm{Fe}_{2} \mathrm{O}_{3}$-nanoparticle layers (prepared by drop-casting of NPs dissolved in toluene onto silicon substrates) upon the annealing in vacuum. As for the former (the a panel), the spectra reveal changes at annealing at $500{ }^{\circ} \mathrm{C}$ : A new peak at about $2 \theta=45$ degree emerges, which dominates for higher annealing temperatures. The peak is attributed to the reduced $\mathrm{Co}_{3} \mathrm{~F}_{7}$ phase with the primitive cubic cell. The original $\mathrm{CoFe}_{2} \mathrm{O}_{4}$ phase vanishes almost entirely at $700{ }^{\circ} \mathrm{C}$, as the strongest 311 diffraction is only visible and it is replaced by $\mathrm{FeO}$ and $\mathrm{CoO}$ phases. Concerning the $\mathrm{Fe}_{2} \mathrm{O}_{3}$ nanoparticles (the $\mathrm{b}$ panel), the slight shift of the 440-peak toward the lower $2 \theta$ with the annealing temperature suggests the gradual transformation from the $\mathrm{Fe}_{2} \mathrm{O}_{3}$
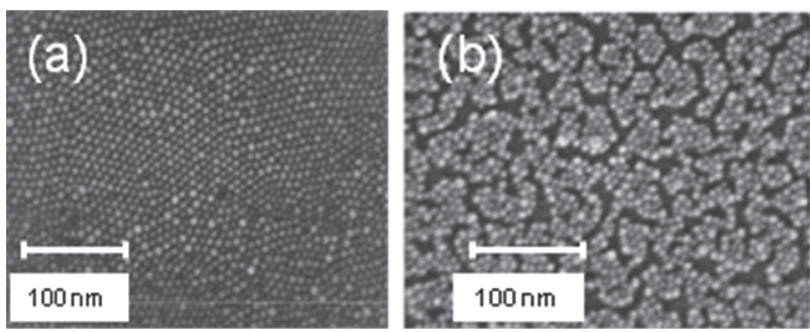

Fig. 1. The SEM mapping of the single $\mathrm{Fe}_{2} \mathrm{O}_{3}$ nanoparticle arrayed monolayer (a) after the preparation by the L-B method and (b) after the surfactant striping by UV irradiation.
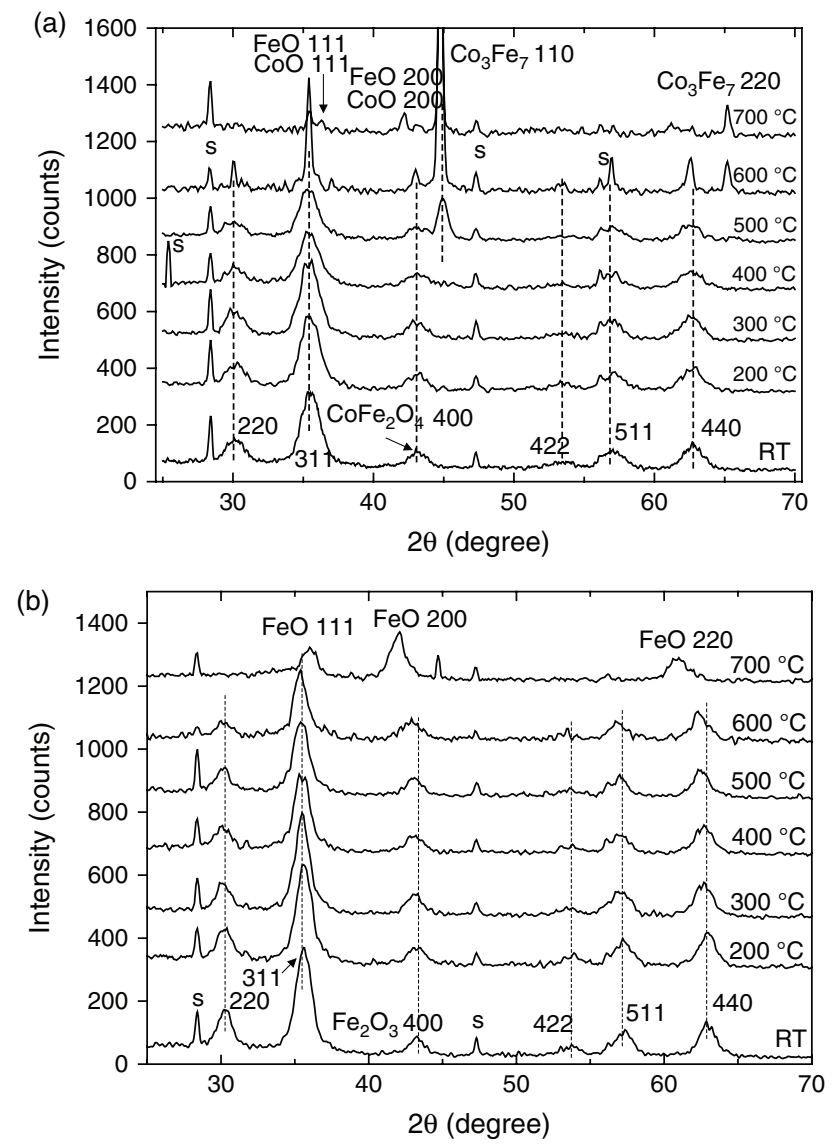

Fig. 2. The $\mathrm{CoFe}_{2} \mathrm{O}_{4}{ }^{-}$and $\mathrm{Fe}_{2} \mathrm{O}_{3}$-nanoparticle structure evolutions ( $\mathrm{a}$ and $\mathrm{b}$ panel, respectively) in dependence of the annealing temperature at pressure of about $10^{-6} \mathrm{~Pa}$ yielded by X-ray diffraction.

to $\mathrm{Fe}_{3} \mathrm{O}_{4}$ phase, thereby confirming the partial reduction too. Besides, the formation of a new $\mathrm{FeO}$ phase with areacentred cubic lattice is indicated at $700{ }^{\circ} \mathrm{C}$. Both characterizations suggest that the $\mathrm{CoFe}_{2} \mathrm{O}_{4}$ and $\mathrm{Fe}_{3} \mathrm{O}_{4}$ nanoparticles are rather stable up to at least about $400{ }^{\circ} \mathrm{C}$ and $600{ }^{\circ} \mathrm{C}$, respectively.

$\mathrm{Fe}_{3} \mathrm{O}_{4}$ oxidizes into $\mathrm{Fe}_{2} \mathrm{O}_{3}$ upon the annealing in air and/or UV irradiation. The oxidation of $\mathrm{Fe}_{3} \mathrm{O}_{4}$ to the final $\mathrm{Fe}_{2} \mathrm{O}_{3}$ phase at the ageing in air was confirmed by the X-ray absorption near-edge spectroscopy (XANES) characterization. This is shown in Figure 3, where the absorbance at the Fe $K$-edge $(7112 \mathrm{eV})$ of a film formed by $10 \mathrm{ML}$ of $\mathrm{Fe}_{2} \mathrm{O}_{3}$-nanoparticles closely resembles to the spectrum of the $\mathrm{Fe}_{2} \mathrm{O}_{3}$ powder. ${ }^{16}$ The $2 \mathrm{ML}$ - and $5 \mathrm{ML}$ thick nanoparticle layers have shown virtually the same spectra.

\subsection{Sensing Properties}

The sensor response, i.e., the resistivity upon the detected gas/vapours exposure, $R_{\mathrm{NO}_{2}}$ or $R_{\text {acetone }}$, ratioed to the resistivity upon the dry air, $R_{\text {air }}$, has been investigated in dependence on the sensor temperature, number of monolayers, and the detected gas concentration. 


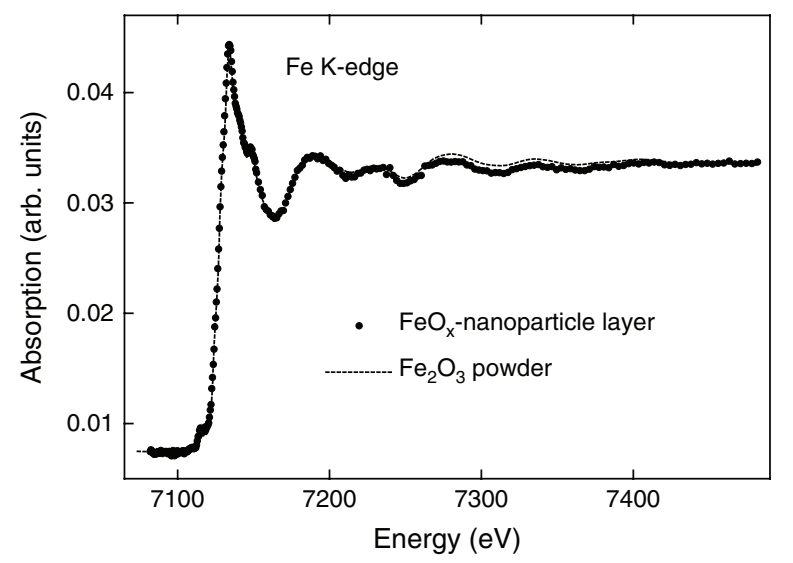

Fig. 3. The XANES spectra of 10 monolayers of self-assembled $\mathrm{Fe}_{2} \mathrm{O}_{3}$ nanoparticle (points) at the $\mathrm{Fe} K$-edge (7112 eV) compared to those of the $\mathrm{Fe}_{2} \mathrm{O}_{3}$ powder (dotted line), the latter being adopted from Ref. [16]. The spectra have been normalized to allow their detailed comparison.

\subsubsection{Response to Acetone Vapours}

Figures 4(a), (b) show responses of $\mathrm{Fe}_{2} \mathrm{O}_{3}$ - and $\mathrm{CoFe}_{2} \mathrm{O}_{4}$ films with various thickness in dependence of the acetone concentration at $400{ }^{\circ} \mathrm{C}$ (left) and $500{ }^{\circ} \mathrm{C}$ (right). The response of the $\mathrm{CoFe}_{2} \mathrm{O}_{4}$ to acetone vapours is
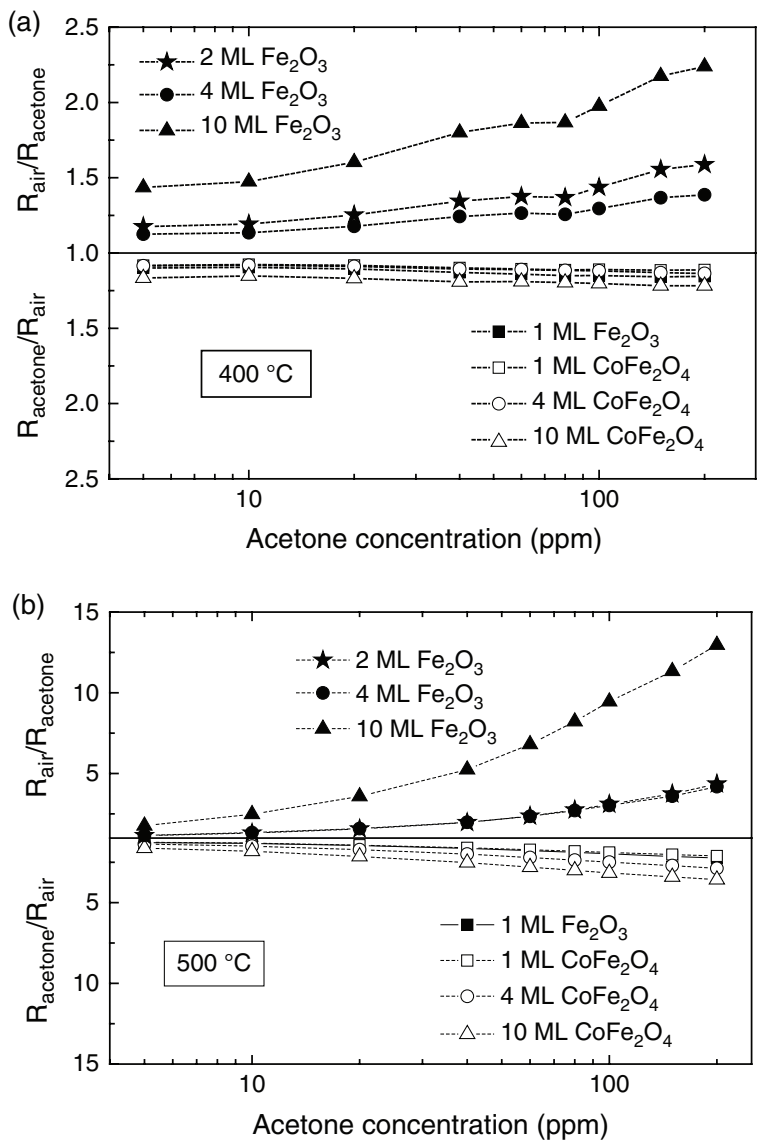

Fig. 4. The response of the $\mathrm{Fe}_{2} \mathrm{O}_{3}$ and $\mathrm{CoFe}_{2} \mathrm{O}_{4} \mathrm{NP}$ sensors with 1,2 , 4 , and $10 \mathrm{MLs}$ to the varying acetone concentration measured at $400{ }^{\circ} \mathrm{C}$ ((a) panel) and $500{ }^{\circ} \mathrm{C}$ ((b) panel). generally lower than that of $\mathrm{Fe}_{2} \mathrm{O}_{3}$, while the responses of $\mathrm{Fe}_{2} \mathrm{O}_{3}$ (except the 1 ML-thick film) and $\mathrm{CoFe}_{2} \mathrm{O}_{4}$ are reversed; the acetone exposure-belonging to reducing gases-decreases (increases) resistance for the former (latter). In other words, the behaviours of the $\mathrm{Fe}_{2} \mathrm{O}_{3}$ and $\mathrm{CoFe}_{2} \mathrm{O}_{4}$-films have $n$ - and $p$-type character, respectively. Interestingly, the $p$-response of the 1 ML-thick $\mathrm{Fe}_{2} \mathrm{O}_{3}$ film switches to the $n$-response with the second and more monolayers. The transformation from $n$ - to $p$-response when going from 1 to $2 \mathrm{ML}$ of $\mathrm{Fe}_{2} \mathrm{O}_{3}$ films has been observed for all explored working temperatures, i.e., 350, 400,450 , and $500{ }^{\circ} \mathrm{C}$. The $n-p$ conductivity transition in metallic oxides has not been observed seldom; the transformation even for a particular metal-oxide semiconductor $\left(\alpha-\mathrm{Fe}_{2} \mathrm{O}_{3}, \mathrm{CoFe}_{2} \mathrm{O}_{4}\right)$ in dependence of the working temperature $^{17,18}$ and/or the gas concentration. ${ }^{17}$ The general ground for the conductivity change has not been clear so far and it has continued to be a matter of discussions.

Figure 5 summarizes the responses of the $\mathrm{Fe}_{2} \mathrm{O}_{3}$ NP layers toward acetone concentration of $5 \mathrm{ppm}$ in dependence on the working temperature. The response increases with the number of monolayers, while the working temperature markedly affects only the thickest film. The best sensitivity of ca 1.8 is about half order lower than that reported for $\mathrm{WO}_{3}$-based nanopowders. ${ }^{9}$

Figure 6 illustrates the time-resolved response of $10 \mathrm{ML}$ $\mathrm{Fe}_{2} \mathrm{O}_{3}$ film to acetone vapours. The response and recovery time were defined as the time required to reach $90 \%$ of the total change. While the response time was about 15 minutes independent of the acetone concentration, the recovery time ranged from about 15 minutes to 55 minutes when going from 5 to $200 \mathrm{ppm}$ of acetone. The response time required to reach $50 \%$ of the change maximum was about 5 minutes.

\subsubsection{Response to $\mathrm{NO}_{2}$}

The exposure to $\mathrm{NO}_{2}$ leads to oxidizing reaction, which may cause the increase of depletion layer and thereby the

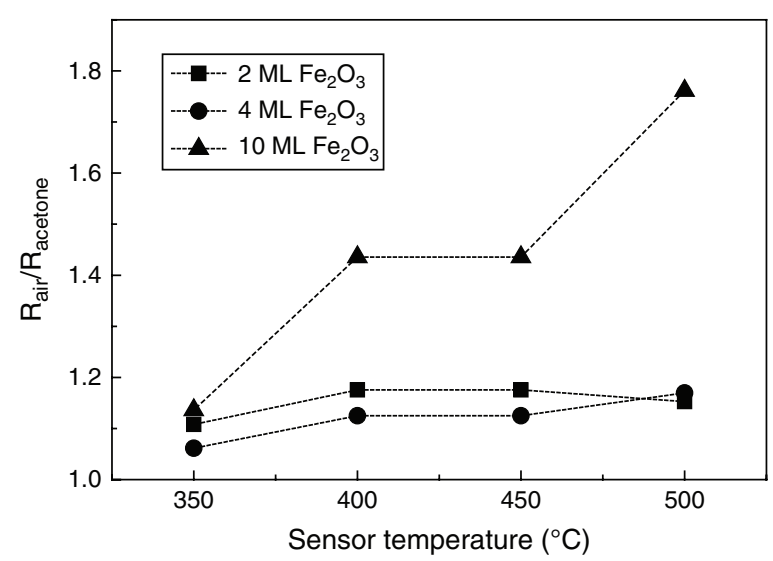

Fig. 5. The temperature dependence of the response of 2,4 , and $10 \mathrm{ML}$ of $\mathrm{Fe}_{2} \mathrm{O}_{3}$ NPs layers to the acetone concentration of $5 \mathrm{ppm}$. 


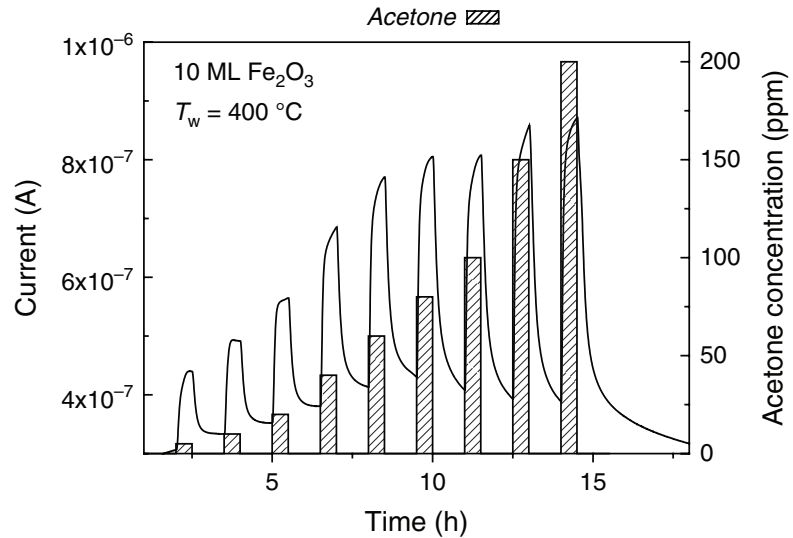

Fig. 6. The time-dependent response of the $10 \mathrm{ML}-\mathrm{Fe}_{2} \mathrm{O}_{3}$ NPs layers in dependence on the acetone concentration. The hatched rectangles depict the time-controlled acetone concentration of sensor's ambient.

height of potential barrier, eventually resulting in the resistance increase. Figure 7 plots the response of $\mathrm{Fe}_{2} \mathrm{O}_{3}$ films consisting of 2, 4 and $10 \mathrm{ML}$ to different concentrations of $\mathrm{NO}_{2}$ in dependence of the working temperature. The response $R_{\mathrm{NO}_{2}} / R_{\text {air }}$ increases with the numbers of monolayers and it is the highest at temperature range of about

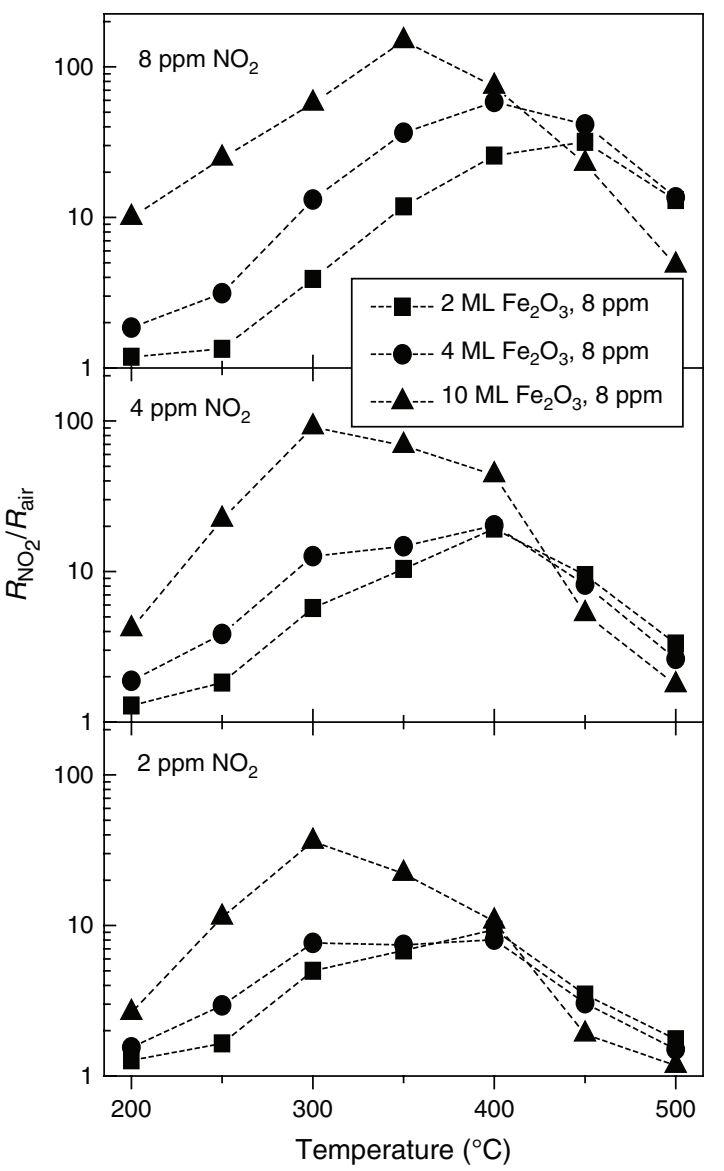

Fig. 7. Responses of $\mathrm{Fe}_{2} \mathrm{O}_{3}$ films with 2, 4, and 10 nanoparticle monolayers toward $\mathrm{NO}_{2}$ with the concentration of 2,4 , and $8 \mathrm{ppm}$.

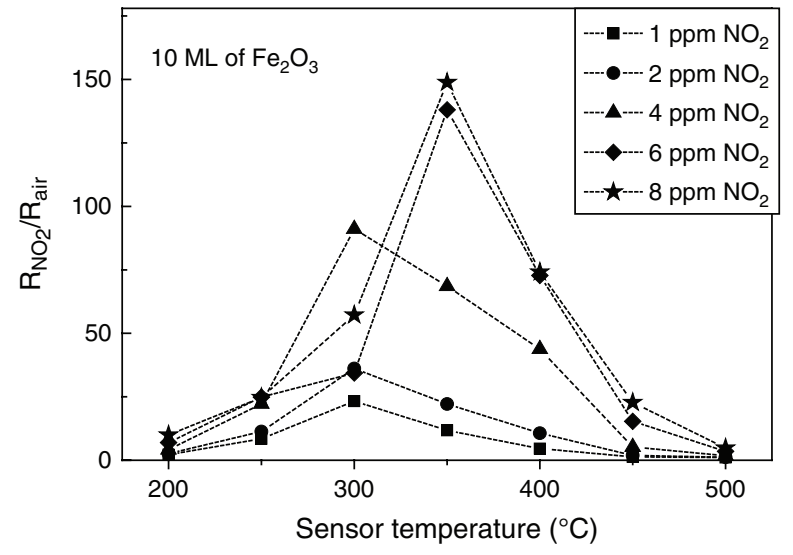

Fig. 8. The temperature dependence of the $\mathrm{NO}_{2}$ response of $10 \mathrm{ML}$ thick $\mathrm{Fe}_{2} \mathrm{O}_{3}$ NP layers.

$300-400{ }^{\circ} \mathrm{C}$. The responses for the $10 \mathrm{ML} \mathrm{Fe}_{2} \mathrm{O}_{3}$, i.e., the films with the highest response, are redrawn in Figure 8. The response of ca 23 to 1 ppm $\mathrm{NO}_{2}$ detected by means of 10 ML-thick film would suggest a good response for the sub-ppm range; the response would rate to usually yielded ones for metal oxide-based sensors. ${ }^{1}$ Concerning $\mathrm{NO}_{2}$, no $p-n$ transformation has been observed. The characterization of dynamic properties (not shown here) suggest the response/recovery times of about 20 minutes in the concentration range from 1 to $8 \mathrm{ppm} \mathrm{NO}_{2}$.

\section{SUMMARY}

The sensing properties of $\mathrm{Fe}_{2} \mathrm{O}_{3}^{-}$and $\mathrm{CoFe}_{2} \mathrm{O}_{4^{-}}$ nanoparticle Langmuir-Blodgett films toward acetone and $\mathrm{NO}_{2}$ have been investigated. Among the explored films with 1, 2, 4, 7, and 10 nanoparticle monolayers, ten $\mathrm{Fe}_{2} \mathrm{O}_{3}$ monolayer-thick films have demonstrated the highest sensitivity, namely of 150 and 23 for 8 and $1 \mathrm{ppm}$ of $\mathrm{NO}_{2}$, respectively. Notably, the good response to $\mathrm{NO}_{2}$ approaching the ppb-range suggests the appropriateness for the detection of nitrate-based explosives. The sensitivity toward acetone concentration in the ppm-range was in the range of units only. The $\mathrm{Fe}_{2} \mathrm{O}_{3}$ and $\mathrm{CoFe}_{2} \mathrm{O}_{4}$ films displayed the reverse conductivity-type behaviour, while the conductivity-type switch was observed for the $\mathrm{Fe}_{2} \mathrm{O}_{3}$ films when going from the one to more monolayers.

Acknowledgment: We acknowledge the financial support by the following project: Scientific Grant Agency VEGA (project number 2/0162/12), bilateral CNR-SAS project 2013-2015, Centre of Excellence SAS for Functionalized Multiphase Materials FUN-MAT, and the EU HASYLAB grant I-20110567 EC.

\section{References and Notes}

1. A. Afzal, N. Cioffi, L. Sabbatini, and L. Torsi, Sens. Actuators B 171-172, 25 (2012).

2. M. M. Rahman, S. Bahadar Khan, A. Jamal, M. Faisal, and A. M. Asiri, Chem. Engn. J. 192, 122 (2012).

Sensor Letters 11, 1-5, 2013 
3. S. Luby, L. Chitu, M. Jergel, E. Majkova, P. Siffalovic, A. P. Caricato, A. Luches, M. Martino, R. Rella, and M. G. Manera, Vacuum 86, 590 (2011).

4. M. W. K. Nomani, D. Kersey, J. James, D. Diwan, T. Vogt, R. A. Webb, and G. Koley, Sens. Actuators B 160, 251 (2011)

5. Z. Yidong, J. Gangcheng, W. Ka Wai, and Z. Zhi, Sensor Lett. 8, 355 (2010)

6. H. Liu, J. Park, and G. Wang, Sensor Lett. 8, 243 (2010).

7. S. F. Bamsaoud, S. B. Rane, R. N. Karekar, and R. C. Aiyer, Sens. Actuators B 153, 382 (2011).

8. D. Wang, A. Chen, and A. K. Jen, Phys. Chem. Chem. Phys. 15, 5017 (2013).

9. L. Wang, K. Kalyanasundaram, M. Stanacevic, and P. Gouma, Sensor Lett. 8, 709 (2010).

10. D. Meng, N. M. Shaalan, T. Yamazaki, and T. Kikuta, Sens. Actuators $B$ 169, 113 (2012).

11. L. You, X. He, D. Wang, P. Sun, Y. F. Sun, X. S. Liang, Y. Du, and G. Y. Lu, Sens. Actuators B 173, 426 (2012).
12. C. Zhang, M. Debliquy, A. Boudiba, H. Liao, and C. Coddet, Sens. Actuators B 144, 280 (2010)

13. S. B. Khan, M. Faisal, M. M. Rahman, and A. Jamal, Talanta 85, 943 (2011)

14. N. P. Zaretskiy, L. I. Menshikov, and A. A. Vasiliev, Sens. Actuators $B$ 170, 148 (2012).

15. K. Rickers, W. Drube, H. Schulte-Schrepping, E. Welter, U. Brüggmann, M. Herrmann, J. Heuer, and H. Schulz-Ritter, AIP Conf. Proc. 882, 905 (2007).

16. M. Newville, XAFS Data Library, Argonne National Laboratory, Argone (URL http://cars9.uchicago.edu/cgi-bin/newville/ Model-Search.cgi).

17. A. Gurlo, M. Sahm, A. Oprea, N. Barsan, and U. Weimar, Sens. Actuators B 102, 291 (2004).

18. X. Chu, D. Jiang, Y. Guo, and C. Zheng, Sens. Actuators B 120, 177 (2006).

19. J. Luo, L. Wang, X. Shi, J. Yin, E. Crew, S. Lu, L. M. Lesperance, and C. J. Zhong, Sens. Actuators B 161, 845 (2012) 